DOI: $10.17223 / 22220836 / 21 / 6$

\title{
О.Л. Иванова
}

\section{ОБРАЗ ТЕРРИТОРИИ. ЗНАКИ ИДЕНТИЧНОСТИ}

\begin{abstract}
В статье рассматривается проблема культурной идентичности жителя определенной территории как отражение процессов регионализации, возникающих в ответ на экспансию транснациональных культурных иенностей. Проблема рассматривается на примере формирования коллективной культурной идентичности жителя Екатеринбурга и Свердловской области как педагогической задачи в процессе художественного образования детей и как элемента стратегии продвижения товаров и услуг предприятий малого бизнеса в сфере художественного производства.

Ключевые слова: коллективная культурная идентичность, образ территории, формирование иенностных ориентиров, педагогика искусства.
\end{abstract}

Степень сложности вопросов, которые приходится решать современному человеку, предполагает необходимость сочетания логических способов познания с возможностями образного мышления и взвешенной эмоциональной оценки ситуации. Освоение новых способов ориентировки в многократно увеличившемся потоке информации требует не столько навыков поиска ответов, сколько способности формулировать вопросы с определенной «позиции наблюдателя».

Выбор точки зрения сегодня весьма проблематичен. Кто мы на самом деле? Где находимся? Что нас окружает, и как мы к этому относимся? Все эти вопросы так или иначе отсылают нас к необходимости обратиться к многоликой категории «идентичность». Проблема идентичности уже достаточно долгое время привлекает внимание исследователей в различных областях гуманитарного знания.

Идентичность рассматривается с позиций философии, психологии, социологии, культурологии, истории. Термин «идентичность» в ряде исследований приходит на смену терминам «самосознание», «самоопределение» [1]. Делаются попытки разработать целостную культурологическую концепцию феномена идентичности [2]. Кроме того, отдельные аспекты понимания культурной идентичности становятся ключевыми в определении, например, маркетинговых стратегий развития субъектов Российской федерации.

В.С. Малахов связывает идентичность современного человека, как категорию социально-гуманитарных наук, с сознательной ориентацией на определенный стиль жизни, «выбирая» который, индивиды формируют свою тождественность с определенной группой, образом жизни, ценностями. По его мнению, в сверхсложных социальных организмах, каковыми являются современные индустриальные (и постиндустриальные) общества, идентичность имеет множественный характер. В процессе социализации индивид научается 
справляться со многими ролями и, соответственно, может иметь множество «идентичностей» [3].

С.С. Степанов, описывая термин «идентичность» с позиций эпигенетической концепции Э. Эриксона, отмечает, что в условиях кризиса традиционных ценностей и размывания авторитетов драматически осложняется самоопределение подрастающего поколения. Общество не в состоянии предложить растущему человеку ценности, ориентируясь на которые он смог бы обрести внутреннюю целостность и гармонию. Те цели и ценности, которые навязчиво пропагандируются, только усугубляют ситуацию в силу своей иллюзорности, практической недостижимости. Авторитет старших не может сыграть тут позитивной роли, поскольку взрослые сами переживают нечто вроде кризиса идентичности, теряясь в непредсказуемых изменениях социума. «Раньше вопрос «Кто я?» автоматически вызывал перечисление традиционных социальных ролей. Сегодня, как никогда, поиски ответа требуют особого мужества и здравомыслия» [4. С. 257].

Несмотря на принадлежность к той или иной научной сфере, в трактовке термина всегда остается аспект индивидуального отношения к чему-либо, формирования оценочных суждений по принципу «мы - они», «свой - чужой».

Осознание «чужого», «другого» происходит только в процессе формирования представлений о «своем». Более того, отнестись к «другому» как к определенной ценности невозможно, пока нет осознания ценности «своего». Это относится ко всем формам личной идентичности, но особенно четко проявляется в формировании культурной, в том числе и коллективной, идентичности.

Особенное значение осознание своей культурной идентичности приобретает в межкультурных коммуникациях в условиях глобализации. Не секрет, что успех делового сотрудничества основывается на понимании культуры и менталитета партнеров по бизнесу и стремлении найти способы взаимодействия, учитывающие интересы всех сторон. Но вот уважение и понимание иной культуры может быть состоятельным только при уважении и знании своей культуры. Поэтому основанием позиционирования территории на внешних и внутренних рынках является осмысление культурной уникальности, ощущение сопричастности к древним и современным ценностям, понимание, чем мы похожи, чем отличаемся, чем можем быть интересны, например, партнерам по бизнесу.

Если жители территории гордятся тем, где живут, ценят уникальность культурного пространства, если в территории имеются возможности и для комфортной жизни, и для бизнеса, - такой город, регион становится привлекательным для инвестиций и в результате активно развивается. То есть бренд территории, который создает «добавленную стоимость» для всего, что делается в городе или регионе, зависит от наличия эмоциональноценностного отношения его жителей. Поэтому формирование коллективной культурной идентичности жителя территории становится важной экономической задачей.

Коллективная культурная идентичность, по мнению Е.П. Матузковой, вырабатывается в ходе саморефлексии общности с помощью механизмов 
идентификации, в основе которых лежит сопоставление, сравнение одной культурной общности с другими. После него происходит осмысление общностью себя как таковой, как целого, обладающего группоидентифицирующими признаками, и тем самым формируется представление общности о себе как самобытной целостности, с которым идентифицируют себя все ее члены. Это представление воплощается в самосознании общности наряду с коллективным бессознательным. Таким образом, коллективная культурная идентичность - это самосознание общности, выступающее как динамическая информационно-знаковая система, являющаяся результатом саморефлексии - конструирования и представления единства общности как самобытного целого на основе культурных ценностей, норм, установок и стереотипов [5].

Интересным объектом для наблюдения за процессом формирования культурной идентичности жителя являются Свердловская область и город Екатеринбург, которые в настоящий момент стремятся занять ведущие позиции в кросскультурных коммуникациях, повысить инвестиционную привлекательность территории, активно развивать международные бизнес-контакты.

Екатеринбург - территория, которая сегодня целенаправленно работает над формированием образа культурной столицы Урала. Из сурового военнопромышленного города, знаменитого, пожалуй, только печально известными событиями, связанными с убийством царской семьи, он становится местом, привлекательным для въездного и внутреннего туризма, настоящим центром культуры и искусства.

Понимание того, что в условиях глобализации, в процессе формирования общемировых экономического, политического, правового, информационного пространств, культурная уникальность территории становится существенным конкурентным преимуществом, той «изюминкой», которая делает регион привлекательным для инвестиций в туризм, современные отрасли производства и сервиса, вызывает к жизни вопросы:

- Что является ядром информационно-знаковой системы, конструирующей и представляющей самобытное целое образа Урала?

- На основе каких культурных ценностей, норм, установок и стереотипов может развиваться общность «житель Урала»?

Интересные параллели можно проследить в формировании коллективной культурной идентичности жителя Екатеринбурга и Свердловской области как педагогической задачи в процессе художественного образования детей и как элемента стратегии продвижения товаров и услуг предприятий малого бизнеса в сфере художественного производства.

Обе эти сферы, в рассматриваемых примерах, связаны поиском визуальных знаков, понятных жителям и гостям Среднего Урала и содержащих образы, репрезентующие социокультурную уникальность территории.

С 2001 по 2008 г. в Свердловской области был реализован культурнообразовательный проект «Северный диалог», авторы: Е.А. Барабанова, О.Л. Иванова, Т.В. Калинина, С.Н. Щавлева-Сивкова. 
Идея проекта родилась из обсуждения творческих работ учеников Екатеринбургской школы искусств № 5, выполненных под руководством талантливого педагога-художника Т.В. Калининой и серии графических листов «Северный цикл» художницы О.А. Житеневой.

Ученики художественной школы изучали и рисовали мифы индейцев Северной Америки. В детских работах ожили загадочные образы Древнего миpa, в котором существовали цивилизации Древней Америки. Неожиданные сюжеты, напряженный колорит графических работ, оригинальность композиционных решений отражали интерес и увлеченность, с которыми дети погружались в неизведанные глубины культуры индейцев. Оказалось, что мифология ушедших эпох будоражит фантазию современных детей, сюжеты и образы затерянного во времени и пространстве мира оказываются важными для детей постинформационной цивилизации.

Северный цикл О. Житеневой - это взгляд художника на древнюю историю Урала. Мотивом для создания Уральского цикла стала потребность художницы, приехавшей на Урал из Красноярска, почувствовать себя частью этого нового для нее природного и культурного пространства.

В семи листах цикла (семь - символ человека) неразрывно связаны между собой мифы, легенды, предания древнейших жителей края: хантов, манси, зырян и их соседей - скифов и славян.

Мифы Древнего Урала в интерпретации современного художника и мифы североамериканских индейцев, изображенные детьми, с одной стороны, очень отличались друг от друга по цвету, композиции, настроению, с другой стороны, в них было что-то неуловимо общее.

Оказалось, что ученики общеобразовательных и художественных школ Свердловской области и Екатеринбурга изучали мифологию и историю искусства Египта, Европы, Америки, Японии и Китая, но ничего не знают о мифологии и искусстве коренных народов Урала. Даже со Сказами Бажова, широко известными на территории Советского Союза несколько десятилетий назад, школьники были почти не знакомы.

Опросы детей и их педагогов показали, что даже если какие-то знания о специфике культурного пространства Среднего Урала и присутствуют, то чаще всего они не входят в структуру ценностных представлений и не позволяют ребенку ощутить сопричастность уникальности территории. Изучение культурных традиций строится, как правило, на визуальном знакомстве с предметами старины, теоретическом знакомстве с обрядами и ритуалами, которым нет места в повседневности, окружающей ребёнка.

На занятиях по народной культуре копируются образцы народного искусства с минимальным варьированием его языковых элементов.

Таким образом, приобщение к культуре приобретает пассивную ознакомительную форму, причем даже в том случае, когда предполагает активную практическую деятельность ребенка. Примером могут служить тщательно расписанные разделочные доски в том или ином приеме росписи, которые не находят места в интерьере современной кухни. 
Предметно-пространственная среда, образ жизни «цифровых аборигенов» [6. С. 27] не дают возможности включить в сферу индивидуальных ценностей объекты иной культуры вне поиска форм для выражения своего отношения к изучаемому явлению.

Оказалось, формирование коллективной культурной идентичности жителя Урала требует особых усилий. Культурные особенности малой родины являются для современного ребенка незнакомой и отчасти чуждой культурной традицией. Организаторы художественных событий, дети, педагоги, деятели культуры и искусства включались в диалог, который начинался с удивления, выявления несовпадения с собой, своим отношением к действительности, со спора с иной традицией и с попытки нахождения компромисса между несовпадающими картинами мира.

Проект включал в себя:

1. Создание условий для общения детей, педагогов, деятелей искусства, в которых у ребенка на эмоциональном уровне, через художественное переживание формируется «участное» отношение к истории и современной жизни родного края в частности, прошлому и будущему планеты Земля в целом.

2. Организацию среды семи художественных выставок-конкурсов работ, посвященных открытию особенностей культуры региона через сопоставление с особенностями культур северных стран: России, Канады, Скандинавских стран, Гренландии, США (Аляска) и т.д.

3. Создание своеобразного актуального художественного пространства, связывающего различные культуры, мир взрослых и мир детей, прошлое и настоящее, в котором проводились художественные акции, включавшие посетителей выставок в интерактивный процесс создания арт-объекта. Пространства, в котором и ребенок, и взрослый могут предъявить результат своей творческой деятельности, где отношение к месту, где ты живешь, воплощено в художественной форме.

4. Проведение перед каждой выставкой методических семинаров для педагогов по актуальным вопросам педагогики искусства и проблемам формирования социокультурной идентичности.

Диалог культур в мероприятиях проекта «Северный диалог» выстраивался через сопоставление архетипических образов. Универсальные образы, называемые архетипами, присутствуют во всех мировых культурах. Начиная с древнейших времен они проявляют себя в любой сфере человеческой деятельности и, конечно, в сфере изобразительного искусства. Например, архетип мирового дерева, символизирующий основные принципы построения мироздания, говорящий о главных законах окружающего мира, можно увидеть и в древних культурах индейцев Северной Америки в виде тотемных столбов и на Урале в синячихинских росписях. Именно архетипы позволяют осуществлять диалог между различными культурами. Благодаря этому диалогу выявляются как общие черты, демонстрирующие единство человеческого рода, так и значимость каждой культуры.

Проект «Северный диалог» позволил и его организаторам, и участникам в какой-то мере определиться с ответами на вопросы: «Кто я?», «Где живу?», «Кто мы для уральской земли - гости, хозяева или разрушители?». 
Дал возможность ребенку соприкоснуться одновременно и с тайнами исторического прошлого, и с тайнами своего внутреннего мира. Педагогу - иначе взглянуть на процесс общения с воспитанниками и поделиться с коллегами уникальными открытиями в области организации обучающего диалога.

Для ребенка стали более понятными произведения традиционного и современного искусства, когда в работе профессионального художника он увидел вариант решения темы, над которой еще недавно работал сам. И взрослый художник, профессионал, в работе ребенка, быть может, впервые запечатлевшем в художественной форме образ изменчивого мира, иначе увидел волнующую его проблему.

Такой диалог, выявив особенности индивидуального отношения к миру, не только показал значимость культур ушедших эпох, но и дал возможность пережить ощущение причастности к созданию сегодняшнего художественного облика Урала, изменить в сознании участников проекта образ-ассоциацию территории (рис. 1).

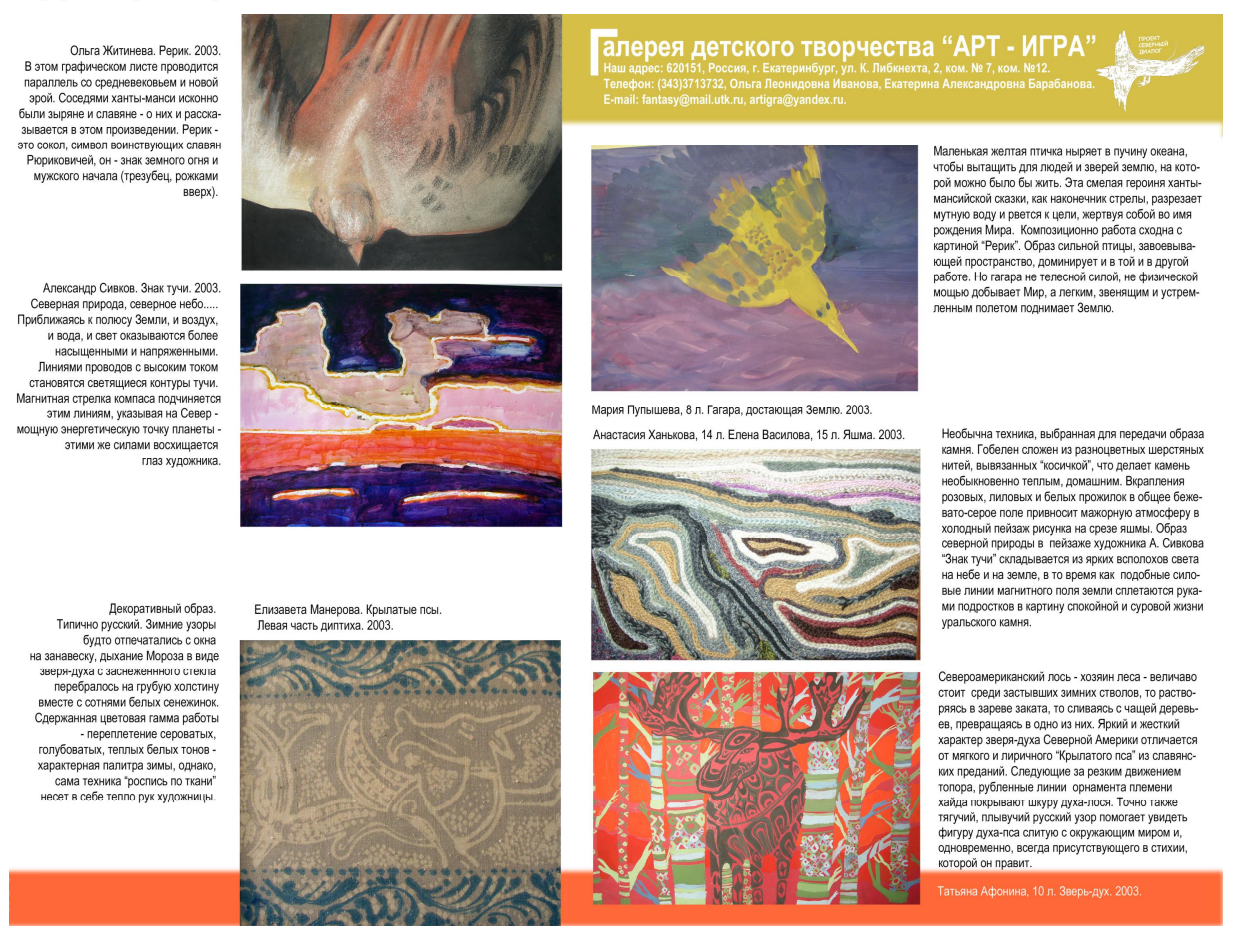

Рис. 1

В мероприятия проекта «Северный диалог» был включен достаточно ограниченный круг участников. В основном это дети из творческих коллективов системы дополнительного образования Свердловской области, их педагоги, художники. Тем не менее их творческие поиски очертили круг тех обра- 
зов-ассоциаций, которые подчеркивают уникальность Урала, вызывают чувство гордости за достояние Отечества.

Осмысленная в процессе реализации проекта проблема неопределенности образа территории в сознании детей и взрослых дает возможность выявить причины кризисного состояния художественного производства на Среднем Урале (рис. 2).

Традиционно самобытность «лица» Среднего Урала определяло художественное производство. Изделия из камня, металла, керамики являлись материальными знаками, репрезентантами образа территории в общероссийский и мировой контекст.

Образ мастера Бажовских сказов, которому в создании художественной формы помогают таинственные силы природы, до сих пор тесно связан с имиджем Урала. До сих пор гости Екатеринбурга упорно ищут в сувенирных лавках изделия уральских камнерезов, ювелиров, гончаров, художников по фарфору.

Но за последние десять лет все знаменитые государственные предприятия по изготовлению художественных изделий исчезли, существующие на данный момент предприятия художественного производства принадлежат сектору малого бизнеса и индивидуального предпринимательства.

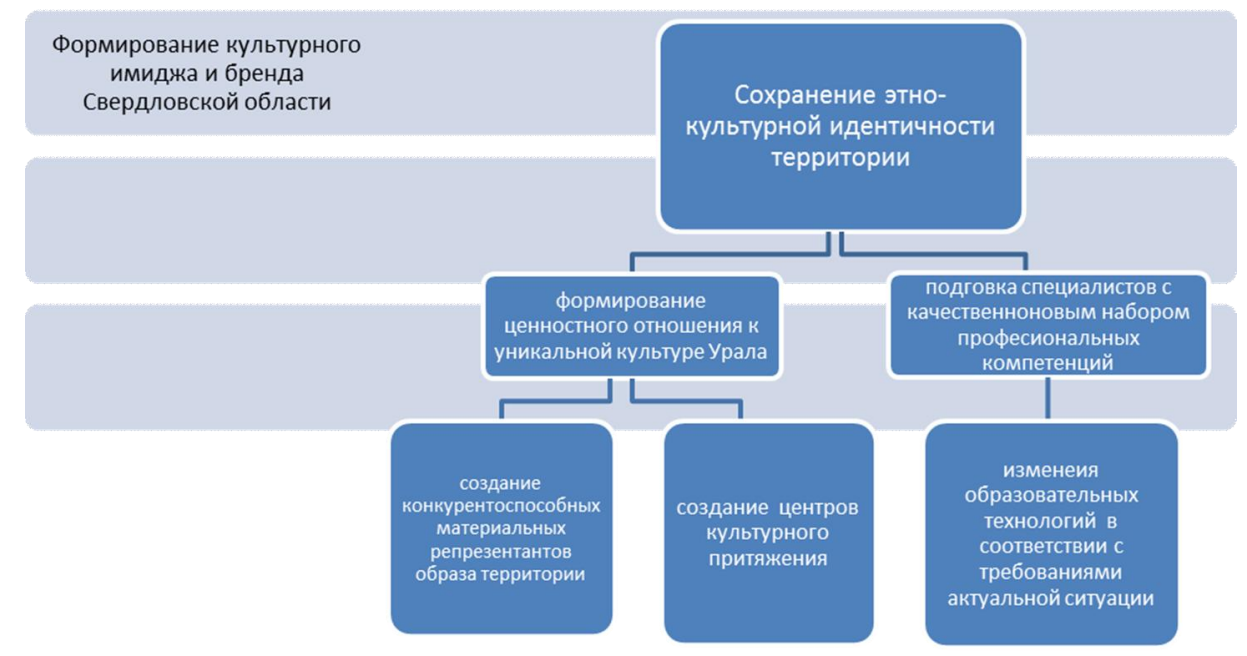

Рис. 2.

Дерево проблем

Мастера, оставаясь носителями технологии, приемов и традиционных художественных образов, стараются сохранить традиции, но их изделия стремительно утрачивают утилитарную значимость, которая прежде обеспечивала потребность в большом количестве изделий. 
Например, нижнетагильский поднос с утратой производственных мощностей по лакировке изделий не может быть использован как кухонная утварь: слабые лаки, нанесенные кустарным способом, не позволяют сохранить уникальную роспись талантливых художников при механических или температурных воздействиях.

Стоимость изделий увеличивается, но они не вписываются в контекст современной предметной среды, внешний вид изделий зачастую не учитывает визуальных предпочтения покупателей. Изменяются свойства товара.

Возможность сохранения уникальных производств появляется в том случае, когда традиционное изделие переходит в категорию знаков территории, сувенирных изделий, дорогих подарков, предметов роскоши, спрос на которые определяется уровнем ценностных отношений населения к культурным традициям региона и качеством изделий.

Неопределенность культурного образа Свердловской области влечет за собой:

- ослабление интереса потребителей к образам традиционного художественного производства;

- отсутствие заинтересованности успешных мастеров в расширении производства;

- стремление производителей художественных изделий встроиться в ценовой рад сувенирной продукции из Китая и других стран, что значительно снижает качество изделий.

В результате происходит следующее:

1. Исчезает уникальная уральская художественная промышленность как культурное явление.

2. Разрушается система подготовки кадров для художественного производства (народных промыслов и художественных ремесел).

3. Уходят из жизни носители художественных традиций.

4. Стремительно изменяется система образцов поведения (идеалов), основанная на таких представлениях, как «значимое» и «незначимое», «правильное» и «неправильное», «наше» и «чужое», «Родина» и «чужбина»;

5. Ослабляется социальная общность, которая обеспечивает возможность объединять «своих» и отличать «чужих» в соответствии с ценностями «духа места»;

6. Отсутствие материальных репрезентантов культуры не дает личности ощущать себя неотьемлемой частью исторического места и культурных традиций, лишает возможности формирования гордости за свою малую Родину и, соответственно, ответственности за ее настоящее и будущее.

Целенаправленное формирование региональной культурной идентичности в сфере художественного производства становится основанием потребительского спроса на продукцию и условием самого существования данных видов художественной деятельности.

В глобализирующемся мире человек может выбрать любую сферу деятельности в соответствии со своими возможностями и установками, посетить любое место на Земле в качестве туриста, может выбрать любое место жи- 
тельства, любой образ жизни, который соответствует его представлениям о комфорте.

Таким образом, привлекательный образ территории, ее культурная самобытность сегодня являются мотивом для выбора цели путешествия, места жительства, инвестиций в развитие производства и социальной инфраструктуры. Поэтому задачи поиска позитивных образовассоциаций, лежащих в основе знаковой системы целостного образа Урала, требуют интеграции усилий региональных властей, бизнеса, культуры, образования:

- в осмыслении возможностей художественного производства (народных художественных промыслов и художественных ремесел) как элемента бренда и ресурса развития территории;

- возобновлении кадрового потенциала художественного производства и сохранении традиций уральского художественного образования;

- формировании регионального культурно-образовательного пространства», объединяющего ресурсы системы образования, учреждений культуры и бизнеса. Формирование единого культурно-образовательного пространства в настоящее время рассматривается как одно из направлений актуализации социокультурного потенциала региона [8];

- организации целенаправленной деятельности по формированию у потребителя ценностного отношения к местным традициям.

Формирование коллективной культурной идентичности процесс не линейный, многослойный, изменчивый, но он приводит к постепенной «кристаллизации», изменению образов-ассоциаций, лежащих в основе знаковой системы, представляющей самобытное целое образа территории. Искусство в этом процессе играет ключевую роль, давая возможность человечеству, по словам А.Г. Асмолова, овладевать границами современности и расширять их, наращивать культурные практики освоения неопределенности [9].

\section{Литература}

1. Антонова Н.В. Самоопределение как механизм развития идентичности / Н.В. Антонова, B.В. Белоусова [Электронный ресурс]. URL: http://cyberleninka.ru/article/n/samoopredelenie-kakmehanizm-razvitiya-identichnosti (дата обращения: 05.01.2016).

2. Япринцева К.Л. Феномен культурной идентичности в пространстве культуры : автореф. дис. ... канд. культурологии. Челябинск, 2006. 20 с.

3. Малахов В.С. Идентичность // Новая философская энциклопедия : в 4 т. М.: Мысль, 2010. T. 2. C. 78-79 [Электронный pecypc]. URL: http://iph.ras.ru/elib/1181.html (дата обращения: 10.01.2016).

4. Степанов С.С. Популярная психологическая энциклопедия. 2-е изд., испр. и доп. М. : Эксмо, 2005. 672 с. [Электронный ресурс]. Цит. по URL: http://psychology.academic.ru/ (дата обращения: 10.01.2016).

5. Матузкова Е.П. Культурная идентичность : к определению понятия // Вестн. Балтийского федерального университета им. И. Канта. 2014. Вып. 2. С. 62-68.

6. Солдатова Г. Они другие? // Дети в информационном обществе. 2013. № 14.

7. Беломоева О.Г. Мировоззренческие истоки модели культурной идентичности // Интеграция образования. 2005. Вып. № 4 [Электронный pecypc]. URL: http://vocabulary. ru/dictionary/487/word/kulturnaja-model (дата обращения: 10.01.2016).

8. Мурзина И.Я. Концепция развития регионального культурно-образовательного пространства // Человек в мире культуры. 2013. № 3. URL: www.http://cyberleninka.ru (дата обращения: 14.11.2014). 
9. Асмолов А.Г. Оптика просвещения : социокультурные перспективы. М. : Просвещение, $2012.447 \mathrm{c}$.

Ivanova Olga L. Ural Federal University named after the first president of Russia B.N. Yeltsin (Yekaterinburg, Russian Federation).

E-mail: prcivanova@yandex.ru,ivanova.olgaleonidovna@yandex.ru

DOI: $10.17223 / 22220836 / 21 / 6$

THE IMAGE OF THE TERRITORY. SIGNS OF IDENTITY

Key words: collective cultural identity, image of the territory, value orientations formation, pedagogy of art, traditional art, contemporary art.

The article examines the problem of cultural identity of a person living on a specific territory, or so-called «regional identity», as a response to regionalization processes appearing at their turn as an answer to transnational cultural values' expansion. A sense of adhering to ancient and modern values and an understanding of cultural uniqueness form the basis for territory positioning on local and foreign markets and are important for intercultural communication in the context of globalization. To analyze the problem the author considers the following example: Ekaterinburg and Sverdlovsk region citizens' collective cultural identity development as a pedagogical task when implementing cultural and educational project «Northern Dialog» on one hand, and on the other hand as goods and services' promotional strategy element for small businesses in a sphere of art production.

These two spheres are connected since they both search for visual signs that are understandable for the people lining in mid Urals as well as for the guests of the region and that contain the images representing cultural uniqueness of the territory that make the region attractive for investments in tourism, modern branches of production and service.

Thus, for example, educational programs in art history leave out specific traits of Ural arts and culture, and especially the part that concerns the ancient history of the region. Ural art of the recent past as well as modern one usually are not included into educational programs. At school students study the history of Egyptian, Greek, American and Eastern cultures. Cultural specifics of the native region («small motherland») are unfamiliar and somewhat alien cultural tradition to a modern child.

«Northern Dialog» project allowed its participants - art events organizers, children, teachers, artists and different specialists in cultural sphere - to get an interesting experience of developing a value attitude towards the culture of the Middle Urals. The learning of Ural mythology and acquaintance with the works of ancient and modern artists started with surprise and discovery of inconsistencies within oneself, and with the way one perceives the reality. It also started with debate with an alien tradition and with an attempt to find a compromise between mismatched world views. The project gave the children an opportunity to come in contact with the mysteries of the ancient past, with the mysteries of their own inner world as well as with specifics of modern cultural environment while creating one's own art object. As for the teachers, the project allowed them to look at the process of communication with their students at a different angle and also to share with colleagues their unique discoveries in a sphere of pedagogy of art as well as their experience of encouraging students' interest in native region's culture.

Businesses that work in a sphere of traditional Ural art production face the necessity of purposeful cultural identity development. Traditional objects produced by stonecravers, potters and metal craftsmen gradually loose their practical functions. Right now it's not just tableware or utensils, but to a greater extent these objects represent the image of the territory: souvenirs, symbols of the region, luxury objects, museum objects. The demand for these objects is defined by the level of people's value attitudes towards cultural traditions of the region. Thus, developing cultural identity of people living in the Urals becomes a key element of art production objects promotion strategies.

Therefore, an attractive image of the territory, it's cultural uniqueness becomes a motive for choosing where to go on vacation, where to live, a motive for investment in production development and social infrastructure. That is why the search for positive images and associations that form the basis of sign system of an authentic image of the Urals require an integrated effort from regional authorities, business, culture and education.

\section{References}

. Antonova, N.V. \& Belousova, V.V. (2011) Samoopredelenie kak mekhanizm razvitiya identichnosti [Self-determination as a mechanism for the development of identity]. Vestnik Moskovskogo gosudarstvennogo gumanitarnogo universiteta. Pedagogika i psikhologiya. 2. pp. 79-92. 
2. Yaprintseva, K.L. (2006) Fenomen kul'turnoy identichnosti v prostranstve kul'tury [The phenomenon of cultural identity in the cultural space]. Abstract of Culturology Cand. Diss. Chelyabinsk.

3. Malakhov, V.S. (2010) Identichnost' [Identity]. In: Stepin, V.S. (ed.) Novaya filosofskaya entsiklopediya: $v 4 t$. [New Encyclopedia of Philosophy. In 4 vols]. Vol. 2. Moscow: Mysl'. pp. 78-79.

4. Stepanov, S.S. (2005) Populyarnaya psikhologicheskaya entsiklopediya [Popular Psychological Encyclopedia]. 2nd ed. Moscow: Eksmo.

5. Matuzkova, E.P. (2014) Kul'turnaya identichnost': k opredeleniyu ponyatiya [To the definition of cultural identity]. Vestn. Baltiyskogo federal'nogo universiteta im. I. Kanta - IKBFU's Vestnik. 2. pp. 62-68.

6. Soldatova, G. (2013) Oni drugie? [Are they different?]. Deti v informatsionnom obshchestve. 14.

7. Belomoeva, O.G. (2005) Mirovozzrencheskie istoki modeli kul'turnoy identichnosti [Ideological origins of cultural identity models]. Integratsiya obrazovaniya - Integration of Education. 4. pp. $140-142$.

8. Murzina, I.Ya. (2013) The concept of development of the regional cultural-educational space. Chelovek v mire kul'tury. 3. pp. 3-14. (In Russian).

9. Asmolov, A.G. (2012) Optika prosveshcheniya: sotsiokul'turnye perspektivy [The optics of education: Sociocultural perspectives]. Moscow: Prosveshchenie. 